\section{Coverage and yield of entry and follow-up screening for tuberculosis among new immigrants}

\author{
C. Erkens*, E. Slump*, M. Kamphorst" ${ }^{\#}$ S. Keizer`, P.J.H.J. van Gerven*, R. Bwire*,

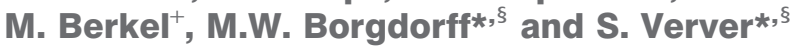

ABSTRACT: The aim of the present study was to determine the effectiveness of entry screening for tuberculosis and biannual follow-up screening among new immigrants in the Netherlands.

To achieve this, the present authors analysed screening, prevalence and incidence data of 68,122 immigrants, who were followed for 29 months. Patients diagnosed within 5 months and 629 months after entry screening were considered to be detected at entry and during the follow-up period, respectively.

Coverage of the second to fifth screening rounds was $59,46,36$ and $34 \%$, respectively. Yield of entry screening was 119 per 100,000 individuals, and prevalence at entry was 131 per 100,000. Average yield of follow-up screening was highest among immigrants with abnormalities on chest radiography (CXR) at entry (902 per 100,000 individuals). When excluding these, yield of follow-up screening was 9, 37 and 97 per 100,000 screenings for immigrants from countries with tuberculosis incidences of $<100,100-200$ and $>200$ per 100,000, respectively. The incidence during follow-up in individuals with a normal CXR was 11, 58 and 145 per 100,000 person-yrs follow-up in these groups. The proportion of cases detected through screening declined per screening round from 91 to $31 \%$.

Yield of entry screening was high. Overall coverage and yield of follow-up screening was low. Follow-up screening of immigrants with a normal chest radiograph from countries with an incidence of $<200$ per 100,000 individuals was therefore discontinued.

KEYWORDS: Chest radiograph, incidence, migrants, prevalence, screening, tuberculosis

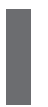
Western Europe, approximately half of the tuberculosis (TB) patients are of foreign origin [1]. In the Netherlands, $\sim 1,000-$ 1,400 patients with active $\mathrm{TB}$ are diagnosed yearly, of whom $68 \%$ are foreign-born individuals [2]. In 2004, the incidence of all forms of TB among foreign-born individuals was 52.4 per 100,000, 17 times the incidence in Dutch-born individuals (3.1 per 100,000 population).

Active case-finding in risk groups is an important strategy for TB control in low-prevalence countries in the elimination phase [3]. In 1995, a risk group policy was formulated in the Netherlands. The Committee for Practical TB Control and the National Health Council defined a risk group for $\mathrm{TB}$ as a (sub)population with an incidence of $>50$ per 100,000 population, $\sim 10$ times the rate in the general Dutch population [4].

Screening for active TB is mandatory for all immigrants from non-Western countries intending to stay longer than 3 months in the
Netherlands [5]; at the time of the study this included all countries except the European Union, Australia, Canada, Iceland, Israel, Japan, Monaco, New Zealand, Norway, Surinam, Switzerland and the USA. Immigrants applying for a residence permit in the Netherlands are referred by the Immigration Department to the Municipal Health Services (MHSs) for TB screening. Screening is performed by chest radiograph (CXR) in individuals aged $>12$ yrs. Asymptomatic children aged $<12$ yrs who have not been vaccinated with bacille Calmette-Guerin (BCG) are tested with a tuberculin skin test (TST) [6, 7]. In some MHSs, individuals not vaccinated with BCG and aged $<25$ yrs are screened with TST. Immigrants aged $>12$ yrs are offered voluntary follow-up screening by CXR every 6 months for a period of 1 or 2 yrs depending on the MHS. CXRs are read within 2 working days by trained TB specialists or pulmonologists. All individuals with any abnormalities in CXR or with positive TST are subjected to medical examination. Further diagnosis with
AFFILIATIONS

*KNCV Tuberculosis Foundation, The Hague,

\#Municipal Health Service Rotterdam, Rotterdam,

"Municipal Health Service Amsterdam, and

${ }^{\S}$ Dept of Infectious Diseases, Tropical Medicine and AIDS, Academic Medical Centre, University of Amsterdam, Amsterdam, and ${ }^{+}$Municipal Health Service Hart voor Brabant, Tilburg, The Netherlands.

CORRESPONDENCE

C. Erkens

KNCV Tuberculosis Foundation

P.O. Box 146

2501 CC The Hague

The Netherlands

Fax: 31703584004

E-mail: erkensc@kncvtbc.nl

Received:

October 192007

Accepted after revision:

February 072008

SUPPORT STATEMENT

This study was funded by the Dutch Health Research and Development Council Prevention Programme (ZON-Mw; project number 2200.0043).

STATEMENT OF INTEREST None declared. 
sputum microscopy and culture is performed in any TB suspect. Individuals with suspected extrapulmonary $\mathrm{TB}$ are usually referred to hospital services for further diagnosis.

TB screening of asylum seekers and other immigrants at entry is common practice in many other low-incidence countries [815]. Apart from the Netherlands, few other countries perform follow-up screening among immigrants with a normal CXR $[11,16,17]$. The effectiveness of TB screening in immigrants has been disputed [12, 18].

The objective of the present study was to assess the effectiveness of the Dutch immigrant screening policy by determining prevalence and incidence of TB disease among immigrants, and the yield and coverage of entry and follow-up screening in subgroups of immigrants, in order to identify risk groups to which screening can be targeted.

\section{METHODS}

Data from the Monitoring for Screening of Immigrants (MSI) system was used $[19,20]$. The MSI system registers individual data on the results of entry and follow-up screening of documented immigrants. It does not include asylum seekers, since they move frequently during their stay. Due to privacy regulations, they are not registered by a unique identification number and are therefore difficult to follow over time. MHSs register year of birth, sex, nationality, date and result of CXR and TST, and final result of screening in a special database in Microsoft Excel or in an electronic client register. Data from electronic client registers were extracted for MSI through a query of the database. KNCV Tuberculosis Foundation (the Hague, the Netherlands) collects the data in a central Microsoft Excel database. The present study utilised the data of cohorts entering in the period 1998-2002, including the follow-up period of 29 months after entry until mid 2005. Data were standardised and checked for inconsistencies. To validate data on TB patients in the MSI system, data were compared with the Netherlands Tuberculosis Register (NTR) [2] using year of diagnosis, year of birth, sex and nationality to match cases. If patients were registered in the MSI system and not in the NTR or vice versa, the MHS was asked for clarification to improve completeness of the database.

\section{Definitions}

The cohort was defined by date of entry screening. Coverage was defined as the number of individuals screened divided by the number of individuals in the target population per screening round. The yield was defined as the number of patients detected per 100,000 individuals screened (for entry screening) and per 100,000 screenings (for follow-up screening). Prevalence was defined as the total number of patients diagnosed (either through screening or passive case finding) per 100,000 individuals screened on entry. The incidence rate was defined as the total number of patients diagnosed (either through screening or passive case finding) per 100,000 person-yrs follow-up in the target population. Patients detected at entry screening or passively $\leqslant 5$ months after entry were considered to be prevalent cases. All patients diagnosed 6-29 months after entry were considered to be incident cases.

The target population per screening was calculated for every screening semester (6-11, 12-17, 18-23 and 24-29 months) as the difference between the number of immigrants screened at entry and the number of immigrants who were detected with active TB, completed the screening according to the MHS or were known to have left the country. Immigrants not known to have left the country were assumed to be still present. In cases where the result of the screening was not coded by the MHS, a completed screening was defined as $>704$ days (23 months) between the first (entry) and the last screening (regardless of attendance at previous screenings).

The result of the initial CXR was classified into five categories as follows: suspected active TB; abnormality, possibly old TB; abnormality, no TB; no abnormalities; and unknown. For the purpose of the analysis, the CXR result was aggregated in three groups: any abnormalities, no abnormalities, and unknown.

Active TB cases were classified by site of disease according to the revised international definitions in TB control [21].

Patients were defined as detected passively when the reason for medical examination leading to the diagnosis of active TB was not immigrant screening. The majority of these patients were diagnosed through the healthcare system, due to presentation of symptoms suggestive of TB.

\section{Analysis}

Stratified risk analysis was performed for age, sex, nationality grouped in countries or continents, incidence groups according to World Health Organization (WHO) estimated incidence in the country of origin in 2002, and abnormalities on the initial CXR. For the sake of brevity, countries of origin with an incidence of $<100,100-200$ and $>200$ per 100,000 individuals were classified as low-, medium- and high-incidence countries.

Patient data are presented for all TB and pulmonary TB (PTB) cases, since CXR is performed to detect PTB, but also frequently detects other forms of TB. Follow-up screening and incidence is only presented for individuals aged $>12$ yrs $(n=61,237)$, since no follow-up screening was offered to children aged $\leqslant 12$ yrs.

\section{RESULTS}

\section{Study groups}

Data were available from 27 MHSs on 70,173 new immigrants entering the Netherlands (fig. 1). A total of 68,122 (97\%) records were complete. The number of immigrants per MHS varied from 105 to 4,456 per cohort-yr. In total, 187 TB patients were identified in the study group, of whom $74 \%$ were bacteriologically confirmed (smear and/or culture positive) among PTB cases and 28\% among extrapulmonary TB cases (table 1). There were 89 prevalent cases and 98 incident cases 6-29 months after entering the country, of which one case was aged $<12$ yrs.

\section{Coverage}

The coverage of the second to fifth screenings was 59, 46, 36 and $34 \%$, respectively (fig. 2). The coverage in the four screening rounds varied considerably between MHSs, ranging from as low as $31,23,6$ and $17 \%$ in one MHS to as high as 87 , 77,67 and 75\% in another. The coverage among individuals from Turkey and Morocco was $8-18 \%$ higher than in individuals from other countries. No relevant differences were 


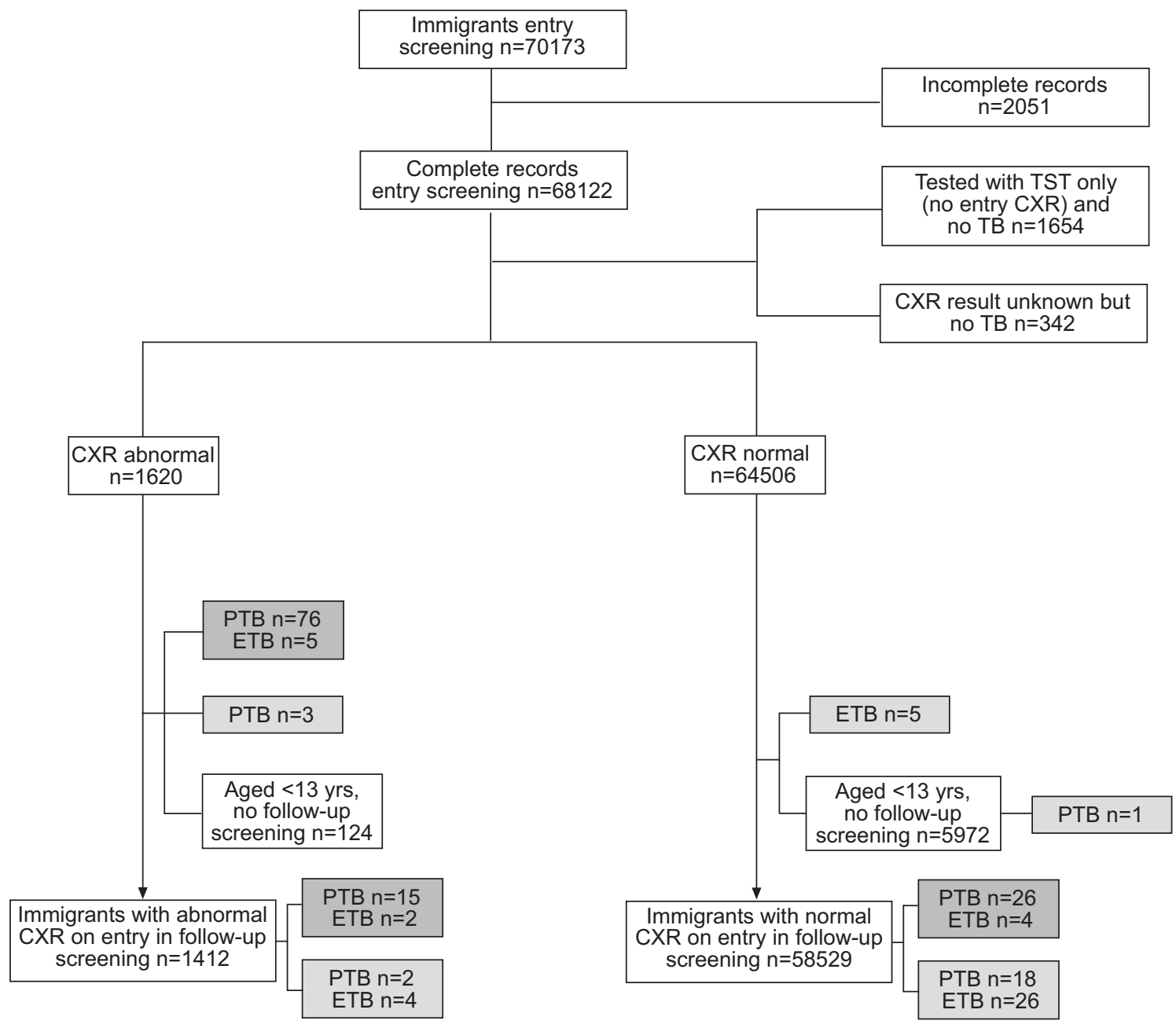

FIGURE 1. Flow chart of results of entry and follow-up screening (6-29 months). 1 : tuberculosis (TB) case detected through screening; 1 : TB case detected passively. TST: tuberculin skin test; CXR: chest radiography; PTB: pulmonary TB; ETB: extrapulmonary TB.

TABLE 1 Number of bacteriologically confirmed cases and percentage of total

\begin{tabular}{ccc} 
0-5 months & \\
\hline $\begin{array}{c}\text { Bacteriologically } \\
\text { confirmed } \\
\text { cases }\end{array}$ & $\begin{array}{l}\text { Total } \\
\text { cases }\end{array}$ & $\%$ \\
& &
\end{tabular}

\begin{tabular}{ccc} 
6-29 months & \\
\hline $\begin{array}{c}\text { Bacteriologically } \\
\text { confirmed } \\
\text { cases }\end{array}$ & $\begin{array}{l}\text { Total } \\
\text { cases }\end{array}$ & $\%$ \\
& &
\end{tabular}

\begin{tabular}{ccc}
\multicolumn{3}{c}{ Total } \\
\hline $\begin{array}{c}\text { Bacteriologically } \\
\text { confirmed } \\
\text { cases }\end{array}$ & $\begin{array}{l}\text { Total } \\
\text { cases }\end{array}$ & $\%$ \\
\hline
\end{tabular}

\section{PTB}

Detected through screening

Passively detected

Total PTB cases

ETB

Detected through screening

Passively detected

Total ETB cases

$\begin{array}{cccc}61 & 76 & 80 & 28 \\ 2 & 3 & 67 & 13 \\ 63 & 79 & 80 & 41\end{array}$

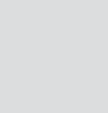

41

20

61

$\begin{array}{cc}5 & 0 \\ 5 & 40 \\ 10 & 20\end{array}$

0
40
20

1
10
11

\begin{tabular}{ccccc}
41 & 68 & 89 & 117 & 76 \\
20 & 65 & 15 & 23 & 65 \\
61 & 67 & 104 & 140 & 74 \\
6 & 17 & & & \\
30 & 33 & 12 & 11 & 9 \\
36 & 31 & 13 & 35 & 34 \\
& & & 46 & 28 \\
\hline
\end{tabular}

PTB: pulmonary tuberculosis; ETB: extrapulmonary TB. * : after entering the Netherlands. 


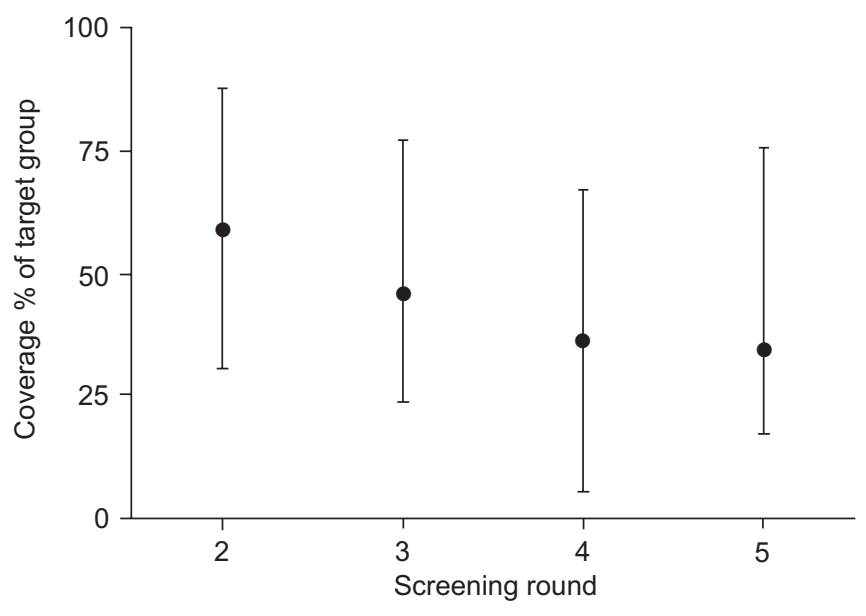

FIGURE 2. Coverage per screening round in 68,122 immigrants screened at entry, as a percentage of the target group screened. Data are presented as averages: 59, 46, 36 and 34 for screening rounds $2-5$, respectively. The error bars indicate the minimum and maximum coverage values observed in the Municipal Health Services.

found between males and females or between other groups of nationalities.

\section{Entry yield and prevalence}

In total, 1,620 individuals were recorded with an abnormal CXR at entry requiring further examination. Active TB was detected in 81 patients. The yield of screening at entry was 119 per 100,000 individuals screened for all forms of TB and 112 per 100,000 for PTB. A further eight patients were detected passively within 5 months of entering the country. Including both passively and actively detected patients, the prevalence of TB at entry was 131 per 100,000 (table 2).

The yield of entry screening was highest in age groups 25-34 and $>45$ yrs, and hardly differed between males and females. The yield of the entry screening for all subgroups varied from 56 to 271 TB cases per 100,000 individuals screened.

\section{Follow-up yield and incidence}

A total of 47 patients aged $>12$ yrs were detected during follow-up screening and 50 patients were detected passively $6-$ 29 months after entering the country. Of the 47 patients detected through follow-up screening, 30 had a normal initial CXR. Among the 20 PTB patients detected passively, two had abnormalities in the initial CXR (fig. 1). In 19 of the 50 TB patients detected passively, the interval between the last screening and diagnosis was $>7$ months.

The yield of follow-up screening was highest among individuals with an abnormality in the initial CXR and who were not diagnosed with TB in the first semester (tables 3 and 4). In 1,412 immigrants with abnormalities in the CXR on entry, follow-up screening detected 17 cases (902 per 100,000 screenings; table 4). Even in the low-incidence nationalities group a high number of cases was detected (411 per 100,000 screenings). The yield of follow-up screening among individuals with a normal CXR was 36 per 100,000 screenings and the incidence 6-29 months after entry was 53 per 100,000 person-yrs followup (table 3). Among subgroups of immigrants from low-, medium- and high-incidence countries, the yield was 9, 37 and 98 per 100,000 screenings, respectively (9, 28 and 89 per 100,000 for PTB cases), and the incidence was 11, 58 and 145 per 100,000 person-yrs follow-up, respectively $(7,35$ and 77 per 100,000 person-yrs for PTB cases).

The yield and incidence during the follow-up period were associated with the incidence in the country of origin. Among individuals with a normal CXR, yield and incidence were higher in females than in males. Yield and incidence were highest in the group aged 25-44 yrs. When the nationality was unknown, yield and incidence were high, but the absolute number of patients of unknown nationality was very low and, therefore, the confidence intervals were wide.

The yield of screening for all forms of TB for the second, third, fourth and fifth screening rounds was 48, 67, 66 and 30 per 100,000 individuals screened, respectively, and 45, 67, 40 and 23 РTB cases per 100,000 individuals screened. In all incidence groups, the yield of screening declined in the last two rounds, even in the high-incidence group, despite a continued high incidence (fig. 3). The proportion of patients detected through screening declined with consecutive screening rounds (fig. 4). There were no significant differences in age, sex or estimated incidence in country of origin between patients found through screening or otherwise detected (data not shown).

\section{DISCUSSION}

The present authors found that the yield of entry screening was 56-271 per 100,000 individuals screened, depending on the subgroup analysed. Furthermore, it was shown that in individuals from low-, medium- and high-incidence countries and with a normal CXR at entry, the yield of follow-up screening during follow-up was 9, 37 and 98 per 100,000 screenings, respectively. Of the prevalent cases, 91\% were detected through screening. Of the incident cases during follow-up, $48 \%$ were found through screening $(67 \%$ of PTB cases). The proportion detected through screening was low in the last two rounds.

Abnormalities in CXR at entry were the most important predictor for development of TB, irrespective of the incidence in the country of origin. Among those with any abnormalities in CXR, $1.6 \%$ were diagnosed with active TB during follow-up. Abnormalities in CXR are often fibrotic lesions due to healed $\mathrm{TB}$ and are a known risk factor for $\mathrm{TB}$ activation [22, 23]. Immigrants with abnormalities in CXR at entry are usually either targeted for more frequent follow-up screening and additional diagnostics or offered preventive therapy.

The present results suggest that, when accepting a cut-off value for the yield of 50 per 100,000 individuals screened, entry screening is useful to detect TB in all immigrants who are currently targeted. Entry screening is also useful to identify an important risk group for intervention, this being individuals with abnormalities in CXR. Follow-up screening can be targeted towards individuals from high-incidence countries. However, the choice in the Netherlands of a cut-off value of 50 per 100,000 for the definition of a target group for screening is arbitrary. It may not be cost-effective to screen all immigrants belonging to groups with a relatively low risk [14, 24]. The study of cost-effectiveness was not the objective of the present study, but consideration of cost-effectiveness may lead to a 
TABLE 2 Yield of screening and prevalence on entry\# in the period 1998-2002

\begin{tabular}{|c|c|c|c|c|c|}
\hline & \multirow{2}{*}{$\begin{array}{c}\text { Screened } \\
\text { individuals } n\end{array}$} & \multicolumn{2}{|c|}{ TB patients $\mathrm{n}$} & \multirow[t]{2}{*}{ Yield" (95\% Cl) } & \multirow[t]{2}{*}{ Prevalence ${ }^{\top,+}(95 \% \mathrm{Cl})$} \\
\hline & & Detected by screening & Found passively & & \\
\hline \multicolumn{6}{|l|}{ Age yrs } \\
\hline$<13$ & 6885 & 8 & 1 & $116(50-229)$ & $131(60-248)$ \\
\hline $13-24$ & 25163 & 20 & 3 & $79(49-123)$ & $91(58-137)$ \\
\hline$>45$ & 2883 & 6 & 1 & $208(76-453)$ & $243(98-500)$ \\
\hline Unknown & 6 & 0 & 0 & & \\
\hline \multicolumn{6}{|l|}{ Sex } \\
\hline Male & 28566 & 33 & 2 & $116(76-155)$ & $123(82-163)$ \\
\hline Female & 39415 & 48 & 6 & $122(87-156)$ & $137(101-174)$ \\
\hline Unknown & 141 & 0 & 0 & & \\
\hline Africa except Morocco & 7603 & 11 & 0 & $144(72-258)$ & $144(72-258)$ \\
\hline Asia except Turkey & 19354 & 31 & 4 & $160(104-217)$ & $181(121-241)$ \\
\hline Central and Eastern Europe & 12554 & 7 & 1 & $56(22-115)$ & $64(28-125)$ \\
\hline Other & 5425 & 6 & 0 & $111(41-241)$ & $111(41-241)$ \\
\hline Unknown & 2122 & 0 & 0 & & \\
\hline \multicolumn{6}{|l|}{ Incidence in country of origin ${ }^{\S}$} \\
\hline$<100$ & 26687 & 17 & 2 & $64(37-102)$ & $71(44-111)$ \\
\hline $100-200$ & 27865 & 33 & 5 & 118 (78-159) & 136 (93-180) \\
\hline$>200$ & 11435 & 31 & 1 & $271(176-366)$ & $280(183-377)$ \\
\hline Unknown & 2125 & 0 & 0 & & \\
\hline \multicolumn{6}{|l|}{ Entry cohort } \\
\hline 1998 & 5608 & 9 & 0 & $160(73-305)$ & $160(73-305)$ \\
\hline Total & 68122 & 81 & 8 & 119 (93-145) & $131(104-158)$ \\
\hline
\end{tabular}

TB: tuberculosis; Cl: confidence interval. * : 0-5 months after entering the Netherlands; ${ }^{\top}$ : per 100,000 individuals screened; ${ }^{+}:$defined as number of cases detected through screening plus number of cases detected passively, divided by number of individuals screened; ${ }^{\S}$ : estimated incidence of total TB per 100,000 individuals in 2002 according to the World Health Organization.

more effective use of resources. Limiting follow-up screening to individuals from high-endemic countries will reduce by 40 $45 \%$ the number of CXRs performed for screening of immigrants and asylum seekers, an estimated total of 35,000 CXRs in 2007.

It can be argued that entry screening could also be restricted to individuals from high-incidence countries, but the present results suggest that migrants are not representative of the total population in the country of origin. For two nationalities, the present results could be compared with the WHO estimates. It was found that among Moroccan and Turkish nationals the prevalence at entry (170 and 101 per 100,000, respectively) was higher than expected from the WHO-estimated prevalence of TB in the country of origin (86 and 44 per 100,000, respectively) [25].
However, incidence during follow-up in these groups (68 and 13 per 100,000, respectively) was lower than the estimated incidence in the countries of origin. This suggests that immigrants from these countries are a selected group with a higher risk for active TB at entry, as are young adult age and lower socioeconomic status groups. In the present study population, $38 \%$ of the population was aged $25-34 \mathrm{yrs}$, the group with the highest prevalence of active TB. The lower incidence during follow-up can be explained by a lower risk of infection in the Netherlands. Early case finding through screening on entry in these groups is likely to contribute to a lower risk of infection among immigrants in the Netherlands.

Other studies in low-incidence countries have reported a persistent high incidence of TB in immigrants, although some 
TABLE 3 Yield of screening and incidence of all tuberculosis (TB) cases during follow-up period (6-29 months) for individuals with normal chest radiography at entry

\begin{tabular}{|c|c|c|c|c|c|c|c|}
\hline & \multirow{2}{*}{$\begin{array}{l}\text { Follow-up } \\
\text { person-yrs }\end{array}$} & \multirow{2}{*}{$\begin{array}{l}\text { Screenings in } \\
\text { rounds } 2-5 n\end{array}$} & \multicolumn{3}{|c|}{ TB patients $\mathrm{n}$} & \multirow[t]{2}{*}{ Yield" $(95 \% \mathrm{Cl})$} & \multirow[t]{2}{*}{ Incidence $^{+}(95 \% \mathrm{Cl})$} \\
\hline & & & Detected & Found passively & Total & & \\
\hline $13-24$ & 57059 & 33237 & 7 & 16 & 23 & $21(8-43)$ & $40(26-60)$ \\
\hline $25-34$ & 57500 & 34693 & 14 & 21 & 35 & $40(22-68)$ & $61(41-81)$ \\
\hline $35-44$ & 18296 & 11910 & 8 & 5 & 13 & $67(29-132)$ & $71(38-122)$ \\
\hline Unknown & 10 & & & & & & \\
\hline \multicolumn{8}{|l|}{ Sex } \\
\hline Male & 56549 & 33232 & 10 & 19 & 29 & $30(14-55)$ & $51(34-74)$ \\
\hline Female & 82194 & 50340 & 20 & 25 & 45 & $40(24-61)$ & $55(39-71)$ \\
\hline Unknown & 283 & 79 & 0 & 0 & 0 & & \\
\hline \multicolumn{8}{|l|}{ Nationality } \\
\hline Central and Eastern Europe & 25973 & 12821 & 2 & 4 & 6 & $16(2-56)$ & $23(8-50)$ \\
\hline Other & 10603 & 5810 & 0 & 1 & 1 & & $9(0-53)$ \\
\hline Unknown & 4236 & 1995 & 2 & 1 & 3 & $100(12-362)$ & $71(15-207)$ \\
\hline \multicolumn{8}{|l|}{$\begin{array}{l}\text { Incidence in country } \\
\text { of origin }\end{array}$} \\
\hline$<100$ & 56079 & 33798 & 3 & 3 & 6 & $9(2-26)$ & $11(4-23)$ \\
\hline $100-200$ & 56702 & 35549 & 13 & 20 & 33 & 37 (19-63) & $58(38-78)$ \\
\hline$>200$ & 22003 & 12300 & 12 & 20 & 32 & $98(50-170)$ & $145(95-196)$ \\
\hline Unknown & 4242 & 2004 & 2 & 1 & 3 & $100(12-360)$ & $71(15-207)$ \\
\hline \multicolumn{8}{|l|}{ Entry cohort } \\
\hline 1998 & 11369 & 7340 & 3 & 4 & 7 & $41(8-119)$ & $62(25-127)$ \\
\hline
\end{tabular}

Cl: confidence interval. ${ }^{\#}:$ n=58,529; ${ }^{*}$ : per 100,000 screenings in rounds $2-5 ;^{+}$: defined as number of cases detected through screening plus number of cases detected passively, per 100,000 person-yrs follow-up; s: estimated incidence of total TB per 100,000 individuals in 2002 according to the World Health Organization.

TABLE 4 Yield of screening and incidence of all tuberculosis (TB) cases during follow-up period (6-29 months) for individuals with abnormal chest radiography at entry\#

\begin{tabular}{|c|c|c|c|c|c|}
\hline \multirow{2}{*}{$\begin{array}{l}\text { Follow-up } \\
\text { person-yrs }\end{array}$} & \multirow{2}{*}{$\begin{array}{l}\text { Screenings in } \\
\text { rounds } 2-5 n\end{array}$} & \multicolumn{3}{|c|}{ TB patients $\mathrm{n}$} & \multirow[t]{2}{*}{ Incidence $^{+}(95 \% \mathrm{Cl})$} \\
\hline & & Detected & $\begin{array}{l}\text { Found } \\
\text { passively }\end{array}$ & Total & \\
\hline
\end{tabular}

TB patients $n$

\begin{tabular}{|c|c|c|c|c|c|}
\hline \multirow{2}{*}{$\begin{array}{l}\text { Follow-up } \\
\text { person-yrs }\end{array}$} & \multirow{2}{*}{$\begin{array}{l}\text { Screenings in } \\
\text { rounds } 2-5 n\end{array}$} & \multicolumn{3}{|c|}{ TB patients $\mathrm{n}$} & \multirow[t]{2}{*}{ Incidence $^{+}(95 \% \mathrm{Cl})$} \\
\hline & & Detected & $\begin{array}{l}\text { Found } \\
\text { passively }\end{array}$ & Total & \\
\hline
\end{tabular}

Yield ${ }^{\top}(95 \% \mathrm{Cl}) \quad$ Incidence $^{+}(95 \% \mathrm{Cl})$

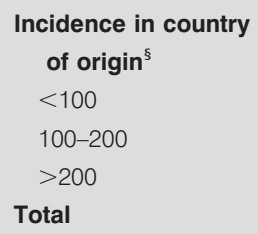
730

363

1884

123
132
677
324

$\begin{array}{cc}730 \\ 3286 & 791 \\ 77 & 363 \\ 241 & 1884\end{array}$

3
9
5
17

$\begin{array}{ll}1 & 4 \\ 3 & 11 \\ 2 & 7 \\ 6 & 23\end{array}$

$\begin{array}{ccc}4 & 411(85-1201) & 324(88-828) \\ 11 & 1138(520-2160) & 828(414-1482) \\ 7 & 1377(447-3215) & 1034(416-2130) \\ 23 & 902(526-1445) & 710(450-1064)\end{array}$

Cl: confidence interval. ${ }^{\#}: n=1,412 ; "$ : per 100,000 screenings in rounds $2-5 ;{ }^{+}:$defined as number of cases detected through screening plus number of cases detected passively, per 100,000 person-yrs follow-up; s: estimated incidence of total TB per 100,000 individuals in 2002 according to the World Health Organization. 

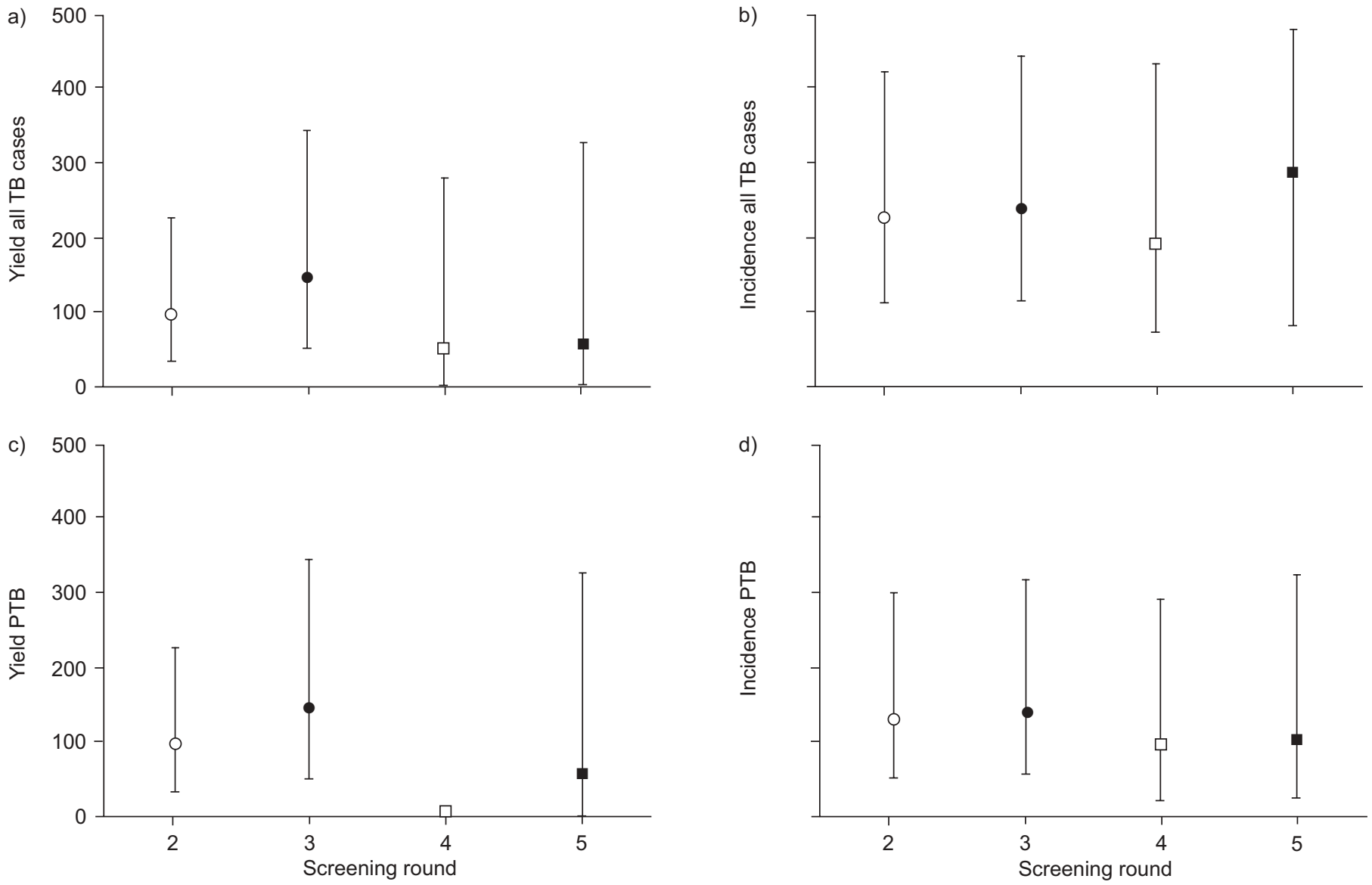

FIGURE 3. Yield ( $a$ and $c$ ) and incidence ( $b$ and $d$ ) of all cases of tuberculosis (TB; $a$ and b) and pulmonary TB (PTB; $c$ and d) by screening round in individuals from countries with an estimated TB incidence $>200$ per 100,000 and normal chest radiography at entry. Screening rounds were performed 6-11, 12-17, 18-23 and 24-29 months after entry. Yield is expressed as n per 100,000 individuals screened and incidence as n per 100,000 person-yrs follow-up. Error bars represent 95\% confidence intervals. For a, b, c and d, respectively: $0: 96,229,96$ and 137; •: 147, 241, 147 and 144; $\square: 50,198,0$ and 99; $\mathbf{\square}: 58,220,58$ and 110.

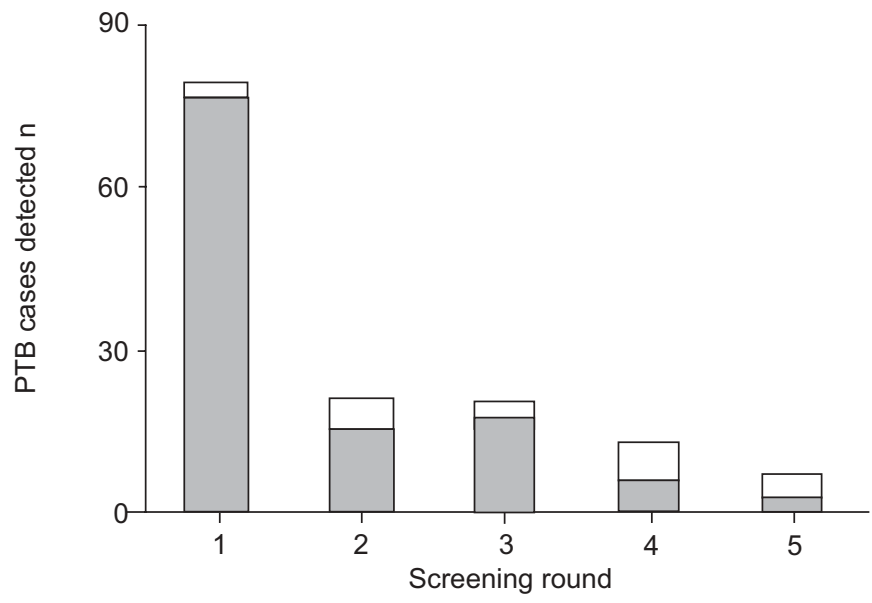

FIGURE 4. Pulmonary tuberculosis (PTB) cases per screening semester according to type of case detection. Screening rounds were performed 0-5, 6-11, 12-17, 18-23 and 24-29 months after entry. $\square$ : screening; $\square$ : passive case finding. The percentage of total cases detected by screening at each round was $96,71,85$, 46 and $43 \%$ for screening rounds $1-5$, respectively. found a decline over time [10, 13, 26-28]. The incidences found in the present study were similar to those in another study in the Netherlands [29], where both regular immigrants and asylum seekers were included. In the study by Vos et al. [29], it was found that incidence remained high many years after immigration. In the present study, it was found that, despite a high incidence throughout the follow-up period in the highincidence group, the proportion of patients detected through screening per consecutive screening round declined, and the yield in the last two rounds was low. The duration of followup screening of 2 yrs is therefore debatable for two reasons: the prolonged higher incidence after entry into the country and the reduced effectiveness of the follow-up screening in the second year. Approximately half of the patients with PTB detected passively could have been detected earlier, since the last screening was $>7$ months before diagnosis; therefore, the yield of follow-up screening could be improved with a better coverage.

The present yield of screening may have been affected by a selection bias, since individuals with symptoms may be more likely to report for screening. Conversely, it is also likely that patients detected passively belong to risk groups that are less likely to report for screening. Not all eligible immigrants 
undergo entry screening [30]. It was estimated from routine surveillance and population data that, in $2002, \sim 70 \%$ of the target immigrant population was screened on entry to the Netherlands [31]. Furthermore, 35 patients from the NTR who were eligible for screening in the study period, but never screened, were detected in the participating MHSs 629 months after entry and, therefore, could not be included in the present study. These patients may represent an immigrant population group with a different risk profile. Therefore, when the coverage of follow-up screening improves, the absolute number of cases detected through screening will increase, but the yield per 100,000 individuals screened may decrease. Therefore, interventions to increase the coverage should address specific subgroups with the highest risk within the target population, such as the younger age groups, and will need to be low cost to maintain the effectiveness of the screening. It may also be more effective to ensure passive case finding among high-incidence groups. The duration of the follow-up period could then be limited to a maximum of $1 \mathrm{yr}$. Alternatively, if it were possible to reduce the pool of latent infected individuals among immigrants, the incidence caused by re-activation would be reduced and follow-up screening could be abolished for all groups.

There are some other limitations concerning the coverage of screening and the representativeness of the data in the present study. The low coverage of the follow-up screening rounds was comparable to earlier studies [6, 24, 32]. The present authors underestimated coverage and, therefore, incidence, since it was assumed that all immigrants were still in the Netherlands during the follow-up period, while some may have left. The number of individuals who left the country amounted to $\geqslant 15 \%$ in the 20 MHSs that registered intended length of stay in the present study and to $26 \%$ in the first $2 \mathrm{yrs}$ in a pilot study at one MHS in 1996 [6]. Marriage and labour are the most important immigration motives for migrants coming to the Netherlands. During the period 1995-2003, more than one third of the migrants came for marriage, $31 \%$ for labour, $13 \%$ for study and $9 \%$ for family unification. Other reasons for migration, for $14 \%$ of migrants, were: being a family member of a migrant; being an au pair; having an internship; and medical treatment [33]. Although the data did not cover all MHSs in the country, the present authors believe the data are representative for immigrants, other than asylum seekers, screened by MHSs in the Netherlands. The participating MHSs are distributed uniformly over the country, giving a fairly even geographic coverage and urban and rural distribution. In 2001 and 2002 the data covered 55-66\% of the total immigrants screened in the Netherlands. Furthermore, trends in coverage and yield are largely comparable between cohorts (tables 2-4). However, the results may not be generalisable to asylum seekers. First, the prevalence among immigrants at entry was lower than had been found for asylum seekers in earlier studies $[23,34]$. This can be explained by the differences in incidence in the countries of origin between immigrants and asylum seekers. Secondly, asylum seekers may have social circumstances that involve a higher risk of infection or breakdown. This may be related to the process of asylum seeking [35]. The present study is also not generalisable to undocumented immigrants, since, by definition, they are not a target group for screening.

\section{Conclusions and recommendations}

The yield of entry screening was high. Entry screening should be continued for all immigrant groups that are currently screened. Follow-up screening for individuals from countries with a low or medium incidence and with no abnormalities on their chest radiographs at entry has been abolished as a result of the present study. The proportion of cases detected through screening declined per screening round, and the coverage and yield of follow-up screening were low after the third round, even in groups from high-incidence countries. This suggests that follow-up screening may be limited to a period of $1 \mathrm{yr}$. Coverage of follow-up screening needs to be increased, especially in subgroups with the highest risk.

\section{ACKNOWLEDGEMENTS}

The present authors would like to thank the staff of the participating Municipal Health Services (all in the Netherlands): Gemeentelijke gezondheidsdienst (GGD) Amsterdam, GGD Westfriesland, GGD Kop van NoordHolland, GGD Noord-Kennemerland, GGD Kennemerland, GGD Zuid-Holland Noord, GGD Den Haag, GGD ZuidHolland West, GGD Midden-Holland, GGD Rotterdam e.o., GGD Utrecht, GGD Rivierenland, GGD Zeeland, GGD WestBrabant, GGD Hart voor Brabant, GGD Zuid-Oost Brabant, GGD Noord- en Midden-Limburg, GGD Zuidelijk ZuidLimburg, GGD Regio Nijmegen, GGD Hulpverlening Gelderland Midden, GGD Gelre-IJssel, GGD Regio Stedendriehoek, GGD Regio Twente, GGD IJssel-Vecht, GGD Flevoland, GGD Fryslân, GGD Drenthe. The authors are also grateful to J. van Burg (Dept of Health, Agency for the Reception of Asylum Seekers, the Hague, the Netherlands), J. Année-van Bavel (Municipal Health Service Hart voor Brabant, Tilburg, the Netherlands) and G. de Vries (Municipal Health Service Rotterdam, Rotterdam, the Netherlands) for providing useful comments on earlier versions of this manuscript.

\section{REFERENCES}

1 EuroTB and the National Coordinators for Tuberculosis Surveillance in the WHO European Region. Surveillance of Tuberculosis in Europe. Report on Tuberculosis Cases Notified in 2005. Saint-Maurice, Institut de Veille Sanitaire, 2007.

2 Royal Netherlands Tuberculosis Association (KNCV) Tuberculosis Foundation. Tuberculosis in the Netherlands 2003 and 2004. KNCV Tuberculosis Foundation, The Hague, 2006.

3 Broekmans JF, Migliori GB, Rieder HL, et al. European framework for tuberculosis control and elimination in countries with a low incidence. Recommendations of the World Health Organization (WHO), International Union Against Tuberculosis and Lung Disease (IUATLD) and Royal Netherlands Tuberculosis Association (KNCV) Working Group. Eur Respir J 2002; 19: 765-775.

4 [TB control policy in risk groups in the Netherlands.] The Hague, Commissie voor Praktische Tuberculosebestrijding, KNCV Tuberculosis Foundation, 1995.

5 [Immigration Act 2000.] Staatsblad 2000; 495. www. overheid.nl. Date last updated: May 17, 2007. Date last accessed: June 30, 2007. 
6 Bwire R, Nagelkerke N, Keizer ST, et al. Tuberculosis screening among immigrants in The Netherlands: what is its contribution to public health? Neth J Med 2000; 56: 63-71.

7 Bwire R, Verver S, Année-van Bavel JA, Kouw P, Keizer ST, Borgdorff MW. [Tuberculosis screening coverage of immigrants: marked attrition in follow-up screenings.] Ned Tijdschr Geneesk 2001; 145: 823-826.

8 Coker R, Bell A, Pitman R, et al. Tuberculosis screening in migrants in selected European countries shows wide disparities. Eur Respir J 2006; 27: 801-807.

9 Coker RJ, Bell A, Pitman R, Hayward A, Watson J. Screening programmes for tuberculosis in new entrants across Europe. Int J Tuberc Lung Dis 2004; 8: 1022-1026.

10 Johnsen NL, Steen TW, Meyer H, Heldal E, Skarpaas IJ, June GB. Cohort analysis of asylum seekers in Oslo, Norway, 1987-1995: effectiveness of screening at entry and TB incidence in subsequent years. Int J Tuberc Lung Dis 2005; 9: 37-42.

11 Rieder HL, Zellweger JP, Raviglione MC, Keizer ST, Migliori GB. Tuberculosis control in Europe and international migration. Eur Respir J 1994; 7: 1545-1553.

12 Bothamley GH, Rowan JP, Griffiths CJ, et al. Screening for tuberculosis: the port of arrival scheme compared with screening in general practice and the homeless. Thorax 2002; 57: 45-49.

13 Zuber PL, McKenna MT, Binkin NJ, Onorato IM, Castro KG. Long-term risk of tuberculosis among foreign-born persons in the United States. JAMA 1997; 278: 304-307.

14 Dasgupta K, Schwartzman K, Marchand R, Tennenbaum TN, Brassard P, Menzies D. Comparison of cost-effectiveness of tuberculosis screening of close contacts and foreign-born populations. Am J Respir Crit Care Med 2000; 162: 2079-2086.

15 LoBue PA, Moser KS. Screening of immigrants and refugees for pulmonary tuberculosis in San Diego County, California. Chest 2004; 126: 1777-1782.

16 Van den Brande $P$, Uydebrouck $M$, Vermeire $P$, Demedts M. Tuberculosis in asylum seekers in Belgium. VRGT (Flemish Lung and Tuberculosis Association). Eur Respir J 1997; 10: 610-614.

17 Aerts A, Vande Gucht V, Vansand V, et al. [Tuberculosis screening in asylum seekers in Belgium, 1999-2003.] Tijdschr Voor Geneeskunde 2005; 61: 1023-1031.

18 Schwartzman K, Menzies D. Tuberculosis screening of immigrants to low-prevalence countries. A costeffectiveness analysis. Am J Respir Crit Care Med 2000; 161: 780-789.

19 Verver S, Bwire R, Borgdorff MW. Screening for pulmonary tuberculosis among immigrants: estimated effect on severity of disease and duration of infectiousness. Int $J$ Tuberc Lung Dis 2001; 5: 419-425.
20 Verver S, van Soolingen D, Borgdorff MW. Effect of screening of immigrants on tuberculosis transmission. Int J Tuberc Lung Dis 2002; 6: 121-129.

21 World Health Organization, International Union Against Tuberculosis and Lung Disease, Royal Netherlands Tuberculosis Association. Revised international definitions in tuberculosis control. Int J Tuberc Lung Dis 2001; 5: 213-215.

22 Styblo K, van Geuns HA, Meijer J. The yield of active casefinding in persons with inactive pulmonary tuberculosis or fibrotic lesions. A 5-year study in tuberculosis clinics in Amsterdam, Rotterdam and Utrecht. Tubercle 1984; 65: 237-251.

23 van Burg JL, Verver S, Borgdorff MW. The epidemiology of tuberculosis among asylum seekers in The Netherlands: implications for screening. Int J Tuberc Lung Dis 2003; 7: 139-144.

24 Dasgupta K, Menzies D. Cost-effectiveness of tuberculosis control strategies among immigrants and refugees. Eur Respir J 2005; 25: 1107-1116.

25 World Health Organisation. Global Tuberculosis Control, WHO Report 2004. Geneva, WHO, 2004.

26 Lillebaek $\mathrm{T}$, Andersen AB, Dirksen A, Smith E, Skovgaard LT, Kok-Jensen A. Persistent high incidence of tuberculosis in immigrants in a low-incidence country. Emerg Infect Dis 2002; 8: 679-684.

27 Watkins RE, Plant AJ, Gushulak BD. Tuberculosis rates among migrants in Australia and Canada. Int J Tuberc Lung Dis 2002; 6: 641-644.

28 Borgdorff MW, Nagelkerke N, van Soolingen D, de Haas PE, Veen J, van Embden JD. Analysis of tuberculosis transmission between nationalities in the Netherlands in the period 1993-1995 using DNA fingerprinting. Am J Epidemiol 1998; 147: 187-195.

29 Vos AM, Meima A, Verver S, et al. High incidence of pulmonary tuberculosis persists for a decade after immigration, The Netherlands. Emerg Infect Dis 2004; 10: 736-739.

30 Baars HWM. [Coverage of TB screening of immigrants in Rotterdam 1993-1994.]Tegen de Tuberculose 2001; 97: 33-35.

$31 \mathrm{KNCV}$ Tuberculosis Foundation. Tuberculosis in the Netherlands 2005; Internet Tables. www.kncvtbc.nl/ publications/ Date last updated: May 17, 2007. Date last accessed: June 30, 2007.

32 Borgdorff MW, Kramer-Hoekstra S, Van Burg J. [Coverage of follow-up TB screening of asylum seekers in the Netherlands.] Tegen de Tuberculose 1998; 94: 12-14.

33 Bijwaard G. [Nearly half of immigrants are only temporary.] Demos 2005; 21: 65-69.

34 Kuyvenhoven JV, Lambregts-van Weezenbeek CS, Annéevan Bavel JA. [Tuberculosis in asylum seekers in the Netherlands.] Ned Tijdschr Geneeskd 1997; 141: 581-584.

35 Menzies D. Tuberculosis crosses borders. Int J Tuberc Lung Dis 2000; 4: Suppl. 2, S153-S159. 